\title{
MOUNTAIN TRACKS DEVELOPMENT METHODOLOGY FOR ADVENTURE RECREATION ACTIVITIES IN GURGHIU MOUNTAINS, ROMANIA
}

\author{
Adrian TORPAN ${ }^{1}$, Mihai VODA ${ }^{2}$
}

DOI: 10.21163/GT_2019. 141.12

\begin{abstract}
:
The focus of this study is mountain recreation trails evaluation for an effective implementation as organized leisure activity in Gurghiu Mountains. Here we show that our tracks classification model can be applied for any Romanian forest. Our research was developed using GIS and geospatial environmental datasets from GoogleEarth combined with field work on every proposed trail in order to assess the morphological features and the ecologically sensitive areas for future preservation. We found that gravel roads and forest exploitation tracks network constitutes the best premises for mountain bikes access in a forested area. We structured them in categories based on difficulty level, surface characteristics and climatic conditions. Furthermore we found that minimum investments are needed to mark and manage these tracks in a cost-effective manner, for the natural forest benefits and protection. Our results show how mountain biking recreation popularity can sustainably contribute to the local communities' development.
\end{abstract}

Key-words: Mountain biking, Gurghiu, Romania, Forest, Trails.

\section{INTRODUCTION}

This paper examines the mountain forest trails potential for organized leisure activities development in Gurghiu Mountains. Studies show that mountain biking will increase in the future due to the new technological advances in electric propulsion and smartphone/GPS orientation devices (Pröbstl-Haider et al., 2018; Voda \& Montes, 2018; Ernawati et al., 2018; Gupta et al., 2018).

This article contributes to understanding why the ecologically sensitive forest areas are more protected if the mountain gravel roads are opened to the public access for recreation activities and properly controlled (Ballantyne et al., 2014). Importantly, it outlines the environmental factors which need to be monitored in future studies and argues that forest exploitation tracks represent the best network for mountain biking expansion. However, recent research suggests that landowners, hunters and the National Forest Administration Authorities are wishing to restrict tourism development in the natural woodlands (Voda et al., 2017; Forest Law 133, 2005; Pröbstl-Haider et al., 2018).

As mountain biking is increasingly seen as a remedy for summer economic ills in other countries with mountainous areas, it is worth examining its potential in Romania which is a pioneer in this process. Switzerland, Germany, Italy and Western Austria opened their forests for mountain bikers, encouraging summer tourism development as a feasible alternative to winter season sports (Pröbstl-Haider et al., 2018; Hardiman \& Burgin, 2013).

This innovative approach makes it possible to analyse the entire Gurghiu Mountains gravel roads network as a functional Geosystem with common and unique attributes given

${ }^{\text {I} F o l k u n i v e r s i t e t e t, ~ J o ̈ n k o ̈ p i n g, ~ S w e d e n, ~ a d r i a n t o r p a n @ y a h o o . c o m ; ~}$

${ }^{2}$ Dimitrie Cantemir University, 540546 Targu Mures, Romania, mihaivoda@cantemir.ro. 
by the various morphometric characteristics, environmental factors and changing climate conditions (Gupta et al., 2018; Voda \& Montes, 2018) and by a quantitative approach (Haidu, 2016). Further, this article contributes to the forest trails classification system, elaborating an efficient assessment methodology that can be securely applied in any natural environment for recreational activities development.

\section{METHODOLOGY}

Given the complexity of natural phenomena that are influencing the adherence on the analysed trails as well as the hazards that can influence the access to the mountain routes, we developed a complex scale (Torpan Scale) to properly quantify the trails difficulty grades for recreational activities (Voda et al., 2017).

The Torpan Scale (TS) was issued to quantify the risks and difficulties of going through the mountain trails for adventure mountain biking. The Torpan Scale uses three main criteria for grading the mountain trails. These are: the morphometric criterion, the adherence criterion and the criterion given by the weather-climatic factors.

The primary index considered in the morphometric criterion assessment was the one given by the slope. In terms of mountain slopes, we took into account the values in the Table 1.

Table 1.

Slope grades under dry track conditions

\begin{tabular}{|c|l|}
\hline Difficulty Degree & Degree of slopes difficulty in dry road conditions \\
\hline Grade 1 & Small slopes: up to $10^{0}$ \\
\hline Grade 2 & Average slopes: up to $10-20^{0}$ \\
\hline Grade 3 & Steep slopes: up to $20-30^{0}$ \\
\hline Grade 4 & Very steep slopes: over $30^{0}$ \\
\hline
\end{tabular}

The adherence criterion is the most sensitive in defining the difficulty classes of the analysed routes because it directly changes the adhesion coefficient that influences the safety on the mountain trails. The classification of the trail elements stability composed of rock fragments after the Torpan Scale has the following values (Table 2):

\section{Difficulty grades given by the non-fixed elements percentage}

Table 2.

\begin{tabular}{|l|l|}
\hline Grade & Percentage of solid non-fixed elements in the macadam component \\
\hline Grade 1 & Has a percentage of solid non-fixed elements up to 20\% \\
\hline Grade 2 & Has a percentage of solid non-fixed elements between 20\% and 50\% \\
\hline Grade 3 & Has a percentage of solid non-fixed elements over 50\% \\
\hline
\end{tabular}

The rocks diameter has a strong limitative factor and presents real risks in the following cases: in combination with slope, increased humidity, sinuous routes, sudden changes in trail`s direction or in combination with wet soils (Fig.1): 


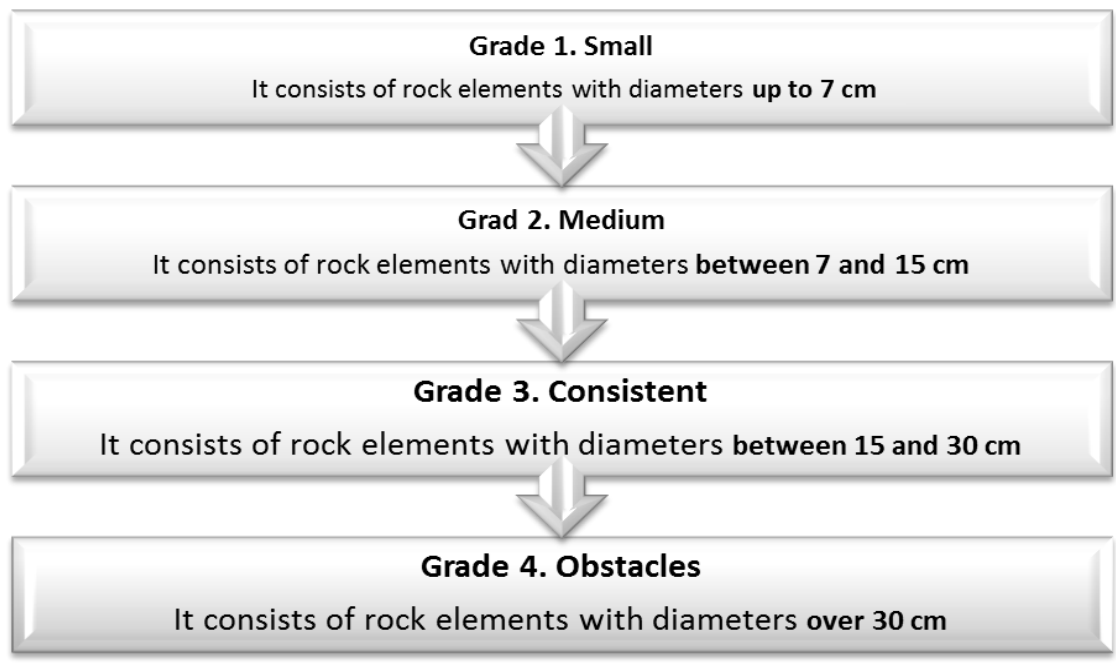

Fig. 1. Rocks diameter difficulty grades.

The climatic factors taken into account for difficulty classes' determination after the Torpan Scale were rainfall, wind and temperature. Atmospheric precipitations are impacting the running surfaces increasing soil moisture depth, stream flow, generating torrents and rock falls that can directly affect the surface layer of mountain trails (Sarpe \& Haidu, 2017; Voda et al., 2018). For the soil trails with or without consistent rocks we have the following degrees of difficulty under various humidity/moisture level (Fig.2):

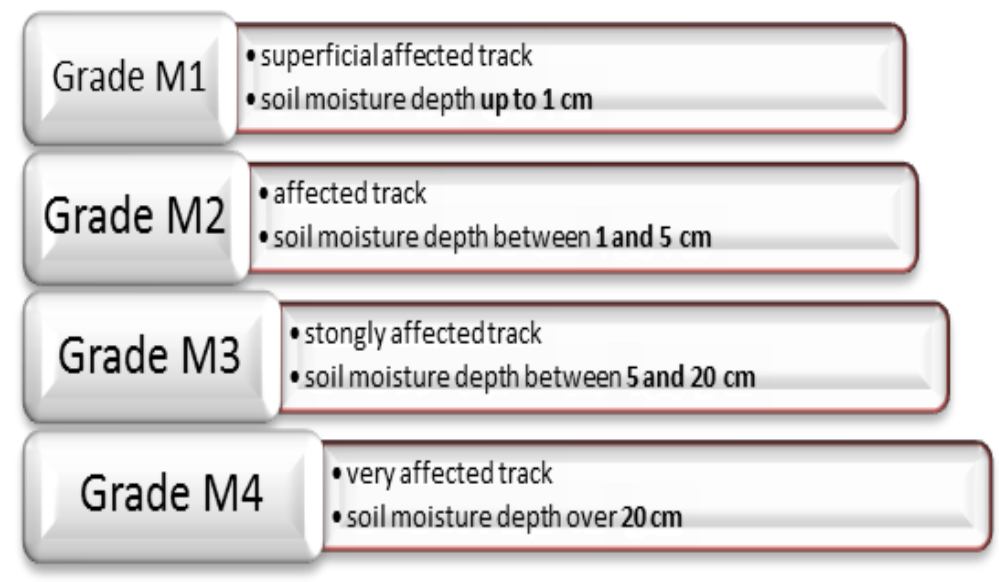

Fig. 2. Gurghiu Mountains MTB routes moisture depth grades.

However, the main limiting factor is given by the slope, which in combination with humidity, changes the slope difficulty classification and presents the following values (Table 3): 
Slope grades under wet track conditions

Table 3.

\begin{tabular}{|c|l|}
\hline Difficulty Degree & Degree of slopes difficulty under wet route conditions \\
\hline Grade 1 & Small slopes: up to $5^{0}$ \\
\hline Grade 2 & Average slopes: up to $5-10^{0}$ \\
\hline Grade 3 & Steep slopes: up to $10-20^{0}$ \\
\hline Grade 4 & Very steep slopes: over $20^{0}$ \\
\hline
\end{tabular}

Grade M1 may occur under the conditions of morning condensation or light rain. It does not affect the grading except in the presence of slopes over 10 degrees. Hence, the evolved erosion processes or the medium and large non-fixed rocks along the route, determine lower slope values for fitting to the same difficulty class level (Fig.3).
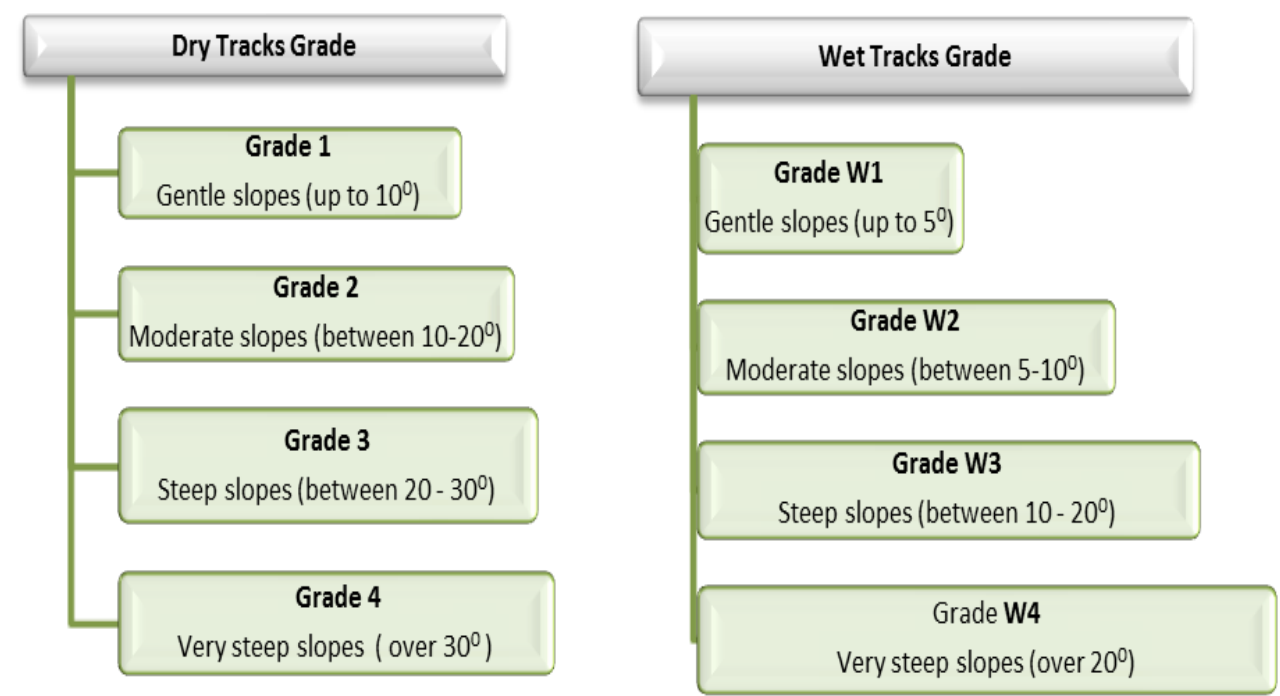

Fig. 3. Wet and dry tracks condition influence on slope grading.

Sudden temperature drops may have a strong restriction role especially in late autumn when early frost phenomena and certain solid precipitation may occur. These are phenomena with an important impact on the trail by radically reducing the adherence along the mountain routes. Lower temperatures associated with strong winds are affecting body thermal comfort, especially for two-wheeled sports practitioners, who are directly exposed to temperature and wind fluctuations. Strong winds can cause forest vegetation collapses along the mountain trails. They can also directly affect paths in high ridge sectors exposed to rough air currents. Especially mountain biking sports enthusiasts can be affected by climate driven trail disruptions.

The combination of all analysed criteria generated the Torpan Scale that includes 10 difficulty classes of mountain routes. It covers the entire range of adventure recreation tracks. The Torpan Scale defines four major categories of difficulty listed in the following tables: Table 4 and Table 5. 
General difficulty categories and the corresponding classification

Table 4.

\begin{tabular}{|l|l|}
\hline Easy/ low-grade routes & Class I, II, III, IV. \\
\hline Medium-difficulty routes & Class V, VI, VII. \\
\hline Difficult routes & Class VIII, IX. \\
\hline Extreme routes & Class X. \\
\hline
\end{tabular}

Under heavy rainfall, considerable temperature drops, and solid precipitations, class VII (medium difficulty routes) may change the category to overall risk class VIII, IX or even $\mathrm{X}$ depending on the degree of damage done to the trail surface (snow or ice presence).

Table 5.

Torpan scale of difficulty categories, classes and grades

\begin{tabular}{|l|l|l|l|l|l|l|}
\hline $\begin{array}{l}\text { Difficulty } \\
\text { category }\end{array}$ & $\begin{array}{l}\text { Difficulty } \\
\text { class }\end{array}$ & $\begin{array}{l}\text { Slope } \\
\text { grades/ } \\
\text { dry track } \\
\text { condition }\end{array}$ & $\begin{array}{l}\text { Slope } \\
\text { grades / wet } \\
\text { track } \\
\text { condition }\end{array}$ & $\begin{array}{l}\text { Solid non- } \\
\text { fixed } \\
\text { elements } \\
\text { grades }\end{array}$ & $\begin{array}{l}\text { Rocks } \\
\text { diameter } \\
\text { difficulty } \\
\text { grades }\end{array}$ & $\begin{array}{l}\text { Routes } \\
\text { moisture } \\
\text { depth } \\
\text { grades }\end{array}$ \\
\hline \multirow{5}{*}{ Easy } & Class I & 1 & 1 & 1 & 1 & 1 \\
\cline { 2 - 7 } & Class II & $1 / 2$ & 1 & 1 & 1 & 1 \\
\cline { 2 - 7 } & Class III & 2 & 1 & $1 / 2$ & 1 & 1 \\
\cline { 2 - 7 } & Class IV & 2 & 1 & 2 & 2 & 1 \\
\hline \multirow{3}{*}{ Medium } & Class V & 2 & 1 & 2 & 2 & 2 \\
\cline { 2 - 7 } & Class VI & $2 / 3$ & 2 & 2 & $2 / 3$ & 2 \\
\cline { 2 - 7 } & Class VII & $2 / 3$ & 2 & $2 / 3$ & $2 / 3$ & $2 / 3$ \\
\hline \multirow{2}{*}{ Difficult } & Class VIII & $2 / 3$ & $2 / 3$ & $2 / 3$ & 3 & $2 / 3$ \\
\cline { 2 - 7 } & Class IX & $3 / 4$ & 3 & $2 / 3$ & $2 / 3 / 4$ & $3 / 4$ \\
\hline Extreme & Class X & 4 & $3 / 4$ & 3 & $3 / 4$ & 4 \\
\hline
\end{tabular}

\section{RESULTS AND DISCUSSIONS}

The analysed area in Gurghiu Mountains is represented by an erosion witness of a volcanic plateau, located around $1300-1415 \mathrm{~m}$ altitude. Spectacular andesitic cliffs are bordering the adjacent river valleys. Fluvial incision and stratigraphic succession are responsible for the high fragmentation depth $(500 \mathrm{~m}$ on average) and the cliffs development. The columns area shows a recent dynamic with gravity detachments and debris slopes at their base. The predominantly soils are andesite soils, developed on the plateau. Lito series soils are found on the debris talus and steep slopes which border the plateau.

The forest exploitation gravel road network is well maintained in Gurghiu Mountains like everywhere in Romania and represents the best way to access and use MTB for recreational purposes (Voda et al., 2014). We found that there are no ecologically sensitive areas on these routes with unchanged morphological features along the years. Crossing the mountains from East to West, the forest exploitation tracks are following the main rivers and their tributaries. We considered them legal tracks and structured the gravel roads network in categories based on slope difficulty level, surface characteristics and climatic conditions. 
The illegal random tracks were also evaluated and monitored because our researches on field revealed more than 25 routes across Gurghiu Mountains that are affecting the natural ecosystems. Used for motorized recreation purposes by hard enduro practitioners, illegal tracks follow small creeks upstream, dense forest deer trails or pasture routes on the volcanic plateau. Those illegal mountain tracks where not considered for our MTB recreational network model (Fig.4).

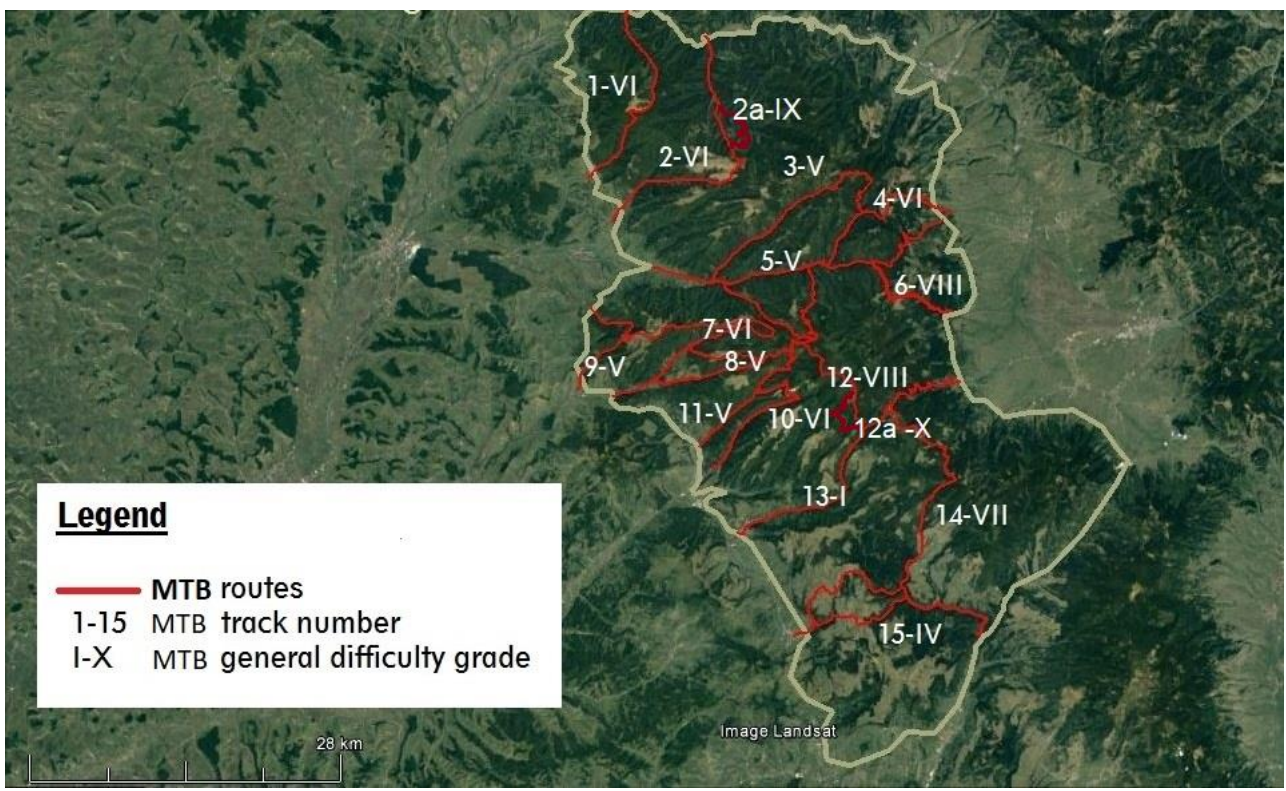

Fig. 4. Gurghiu Mountains tracks classification map.

In order to correctly evaluate the Gurghiu Mountains MTB routes, we analysed two categories of risks that are directly affecting the tracks: natural risks and anthropogenic origin risks. In the natural risks category, the geomorphological risks and weather related risks were included.

The geomorphological risks are closely correlated with the morphometric features of specific volcanic substrate composition with external influences from the hydric and thermic regime, weather-related phenomena (often with a trigger role) and geological risks caused by the major movements of the crust. The most dynamic phenomena that can affect MTB routes today are represented by mass movements, rolling stones, cave-ins, flow hillside, subsidence, landslides and other processes represented by ravines, torrential floods, stream runoffs that can occur on the slope under the gravity direct impact on the gravel roads infrastructure used for MTB activities (Gupta et al., 2018).

The analysis of weather related risks for the Gurghiu Mountains MTB recreational routes required special attention due to their destructive power and the unpredictability factor, which cannot be controlled by man. In practice, they often have a major role in unleashing geomorphological phenomena. Giving rise to a domino effect, the weather phenomena are expanding the various natural risks with direct impact on MTB gravel roads infrastructure (Voda et al., 2014). 
The anthropogenic origin risks are caused by human intervention for deforestation purposes in the Gurghiu Mountains, where the MTB recreational routes were analysed. In most cases human intervention creates phenomena and events with high risk by disrupting natural systems relative equilibrium. The most common human activities impacting on Transylvanian mountains routes are represented by excessive deforestation leading to severe imbalances on local natural woods ecosystems. Mountain biking development will increase transparency diminishing illegal logging activities (Voda and Montes, 2018).

Along the criteria related to MTB routes adherence, climate, natural risks and anthropogenic related risks, the main criteria considered in the MTB accessibility routes assessment is given by track surface morphometric characteristics and route slopes as the main limiting factor analysed through GIS. Also their influence is enhanced or diminished depending on rainfall amount, the presence of freezing temperatures and the slope orientation. GIS analysis revealed that the presence of erosion linear deployment on routes running surfaces (runoff, ravination and torrents) is strongly influenced by the slope degree in which they develop, the slope being the main factor accelerating the expansion of these phenomena.

In general, we found that the easier wet track grades tend to be harder than expected compared to the normal dry condition grades. The remoteness and poor volcanic rock quality in Gurghiu Mountains mean conditions are highly variable. There are some very committing Grade M2-W2 climbs because often, the challenge of the route comes from the fluctuating mountain weather conditions, rather than technical gravel road gradients. Thus the moderate slope characteristics of Grade 2 are becoming as difficult as the steep slopes when the moisture GradeM2 is affecting the tracks. As a case study we evaluated the scenic route of Gurghiu Valley - Sirod Valley - Niraj Valley leading to Campul Cetatii Village. According to the Gurghiu Mountain MTB tracks classification, the route is easily accessible for MTB practitioners in normal dry conditions and positive temperatures. Thus we differentiated the sectors that present moderate Grade 2 slopes, from the gentle variation of the gradient along the route (Grade1) that is less difficult for MTB activities (Fig.5).

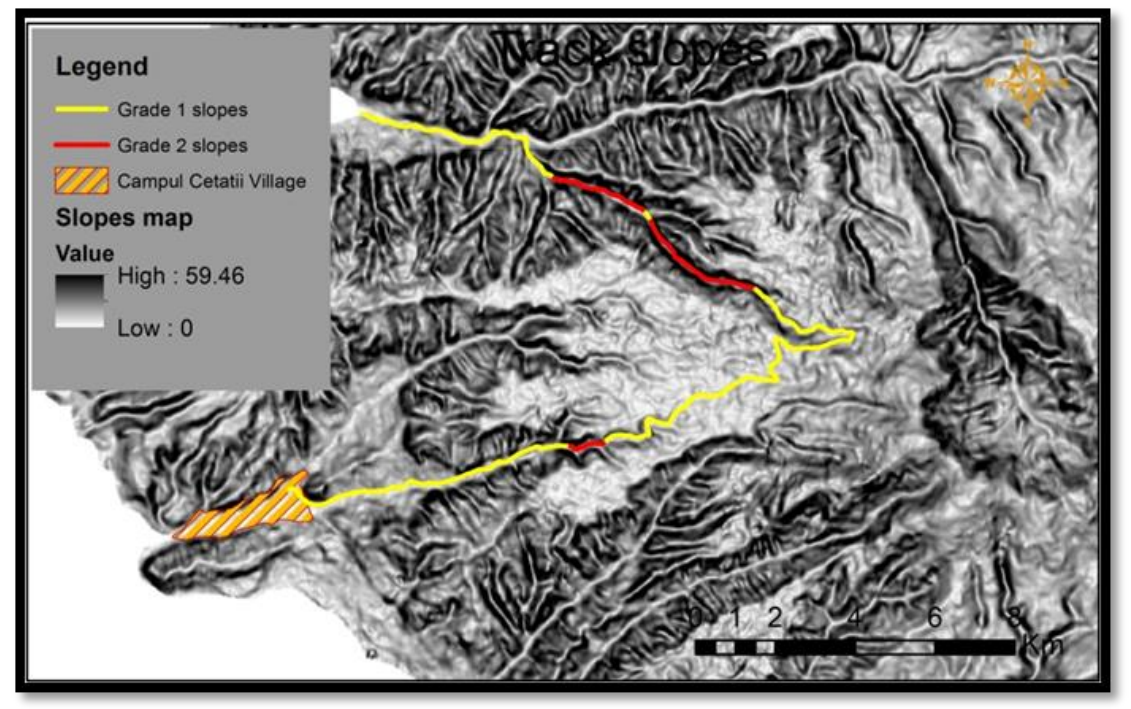

Fig. 5. Gurghiu Valley-Campul Cetatii Village route slope grades map. 
Using GIS and geospatial environmental datasets from GoogleEarth combined with field work, we analysed all the route sections that are exposed to natural and anthropogenic risks (Fig. 6).

Our field research identified eighteen deforestation areas and seven collapses of soilstructure interaction along the Gurghiu Valley - Sirod - Niraj - Campul Cetatii Village track. After this MTB recreational route evaluation, we came to the conclusion that previous uncontrolled deforestation activities determined torrents and ravines development, increased the surfaces of wind exposed areas and led to soil structure collapses.

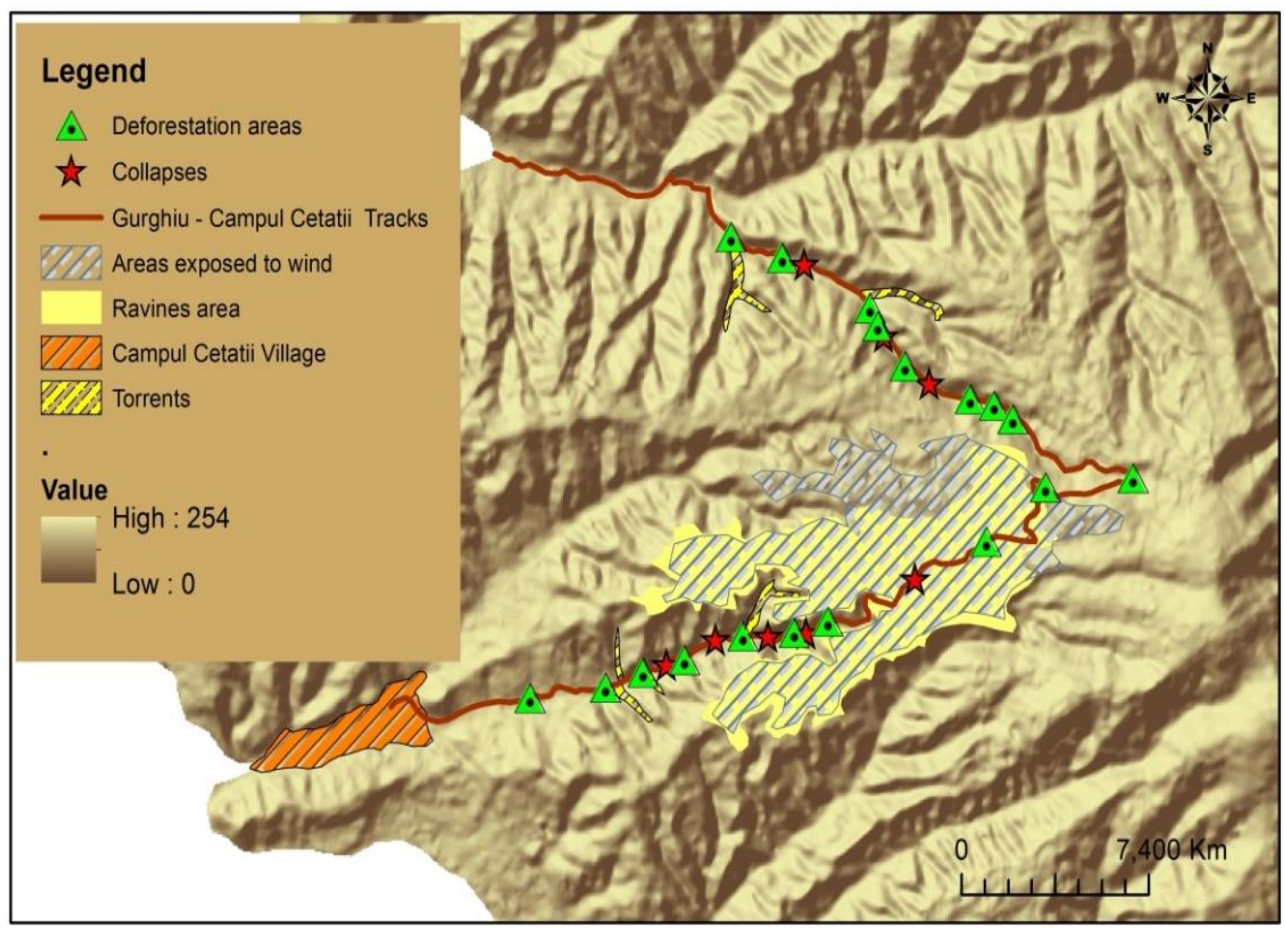

Fig. 6. Mountain bike recreational route risks map.

Romanian National Forest Administration Authorities did not manage deforestation activities accordingly in terms of ecosystem balance maintenance. As a result, in time, the dynamic equilibrium was affected. We assessed the morphological features and the ecologically sensitive areas of the Gurghiu Valley - Sirod - Niraj - Campul Cetatii Village MTB recreational route for future preservation.

We strongly believe that the inclusion of this forest exploitation track in a MTB recreational network constitutes the best premises for Gurghiu mountainous region ecosystems protection and local villages' future sustainable development. We found that National Forest Administration is constantly investing in gravel roads maintenance and cooperates with tourist trails responsible authority for the tracks effective marking. 


\section{CONCLUSIONS}

This article examined a network of more than $1000 \mathrm{~km}$ length. Our study identified 40 off road mountain tracks during six years of field research and proposed an MTB recreation frame model for Gurghiu Mountains. The analysis reveals the recreational potential of the tracks selected from the National Forest Administration gravel roads network which were evaluated, classified and designed following MTB practitioners needs.

Further, the study confirms what MTB recreational tours are offering: the sensation of freedom (that comes especially riding on less crowded mountain routes), pure air to breathe (there are no polluted areas) and beautiful landscapes (spectacular sceneries constitute the main attraction).

Our study results are providing a protocol for the methodological steps used to evaluate forest tracks and create adventure recreational networks. The present research validated $409.8 \mathrm{~km}$ of forest tracks from Gurghiu Mountains including 15 beautiful routes of different general difficulty categories (GDC) with classes from I to X. Most of the tracks have a moderate to low difficulty level, the easiest being number 13 (Trans-Gurghiu) of 30 $\mathrm{km}$ long with I-GDC and the hardest being track number 12 (Fancel-Bucin) with VIII-GDC and $24 \mathrm{~km}$ length.

According to analysis presented in this article, the best MTB recreational track from Gurghiu Mountains is represented by Poieni route (7-VI). Starting in Orsova Village and passing through Gurghiu Meadow- Obarsia Glade-Prislop Glade- Copriana Glade- Breditel Meadow, it follows Niraju Mare Valley downstream to the ending point in Campu Cetatii Village. The longest MTB route has $50 \mathrm{~km}$ of gravel road, forming a IV grade circuit from Corund traditional village to Zetea storage reservoir. The shortest $(9-\mathrm{V})$ has only $3.7 \mathrm{~km}$ length but it is a very important linkage track between Gurghiu and Nirajului river valleys.

Further research is needed to identify the local communities' leisure infrastructure and accommodation possibilities for the mountain biking practitioners. The present study did not examine the bike rental opportunities and bike service availability in the analysed area.

The findings presented in this research give ground for any forest trail evaluation for the inclusion in future outdoor recreational areas. The mountain biking recreation popularity can actively contribute to the sustainable tourism development not only in Gurghiu forests but on any woodland.

\section{R E F E R E N C E S}

Ballantyne, M., Gudes, O., \& Pickering, C.M. (2014) Recreational trails are an important cause of fragmentation in endangered urban forests: A case-study from Australia. Landscape and Urban Planning, 130, 112-124.

Ernawati, N.M., Torpan, A. \& Voda, M. (2018) Geomedia role for mountain routes tourism development. Mesehe and Pisoiu Waterfall comparative study. Geographia Technica, 13 (1), 41 51.

Forest Law 133. (2015) Motorised public acces into the National Forest Fund. [Online]. Available from: http://legea_133_2015_modificare_lege_46_2008_codul_silvic.php [Accessed December 2018].

Google Earth. (2018). Google Earth. [Online]. Available from: www.google.com/earth/ [Accessed August 2018]. 
Gupta, S.K., Negru, R., \& Voda, M. (2018) The Indian Himalaya`s unique attributes: Hemkund Sahib and The Valley of Flowers. Geographia Technica, 13 (2), 62-73.

Haidu, I. (2016) What Is Technical Geography. Geographia Technica, 11(1), 1-5. DOI: 10.21163/GT_2016.111.01.

Hardiman, N., \& Burgin, S. (2013) Mountain biking: downhill for the environment or chance to up a gear? International Journal of Environmental Studies, Vol. 70, No. 6, 976-986.

Pröbstl-Haider, U., Lund-Durlacher, D., Antonschmidt, H., \& Hödl, C. (2018) Mountain bike tourism in Austria and the Alpine region - towards a sustainable model for multi-stakeholder product development, Journal of Sustainable Tourism, 26:4, 567-582, DOI: 10.1080/09669582.2017.1361428

Sarpe, C. A., \& Haidu, I. (2017). Temporal sampling conditions in numerical integration of hydrological systems time series. Geographia Technica, 12 (1), 82- 94.

Voda, A.I, Sarpe, C.A, \& Voda, M. (2018) Methods of maximum discharge computation in ungauged river basins. Review of procedures in Romania. Geographia Technica 13(1), 130-137.

Voda, M., Moldovan, L., Torpan, A., \& Henning, A. (2014) Using GIS for mountain wild routes assessment in order to qualify them for tourism valorisation. Geographia Technica 9 (1), 101108.

Voda, M., Torpan, A. \& Moldovan, L. (2017) Wild Carpathia Future Development: From Illegal Deforestation to ORV Sustainable Recreation. Sustainability, 9(2254), 1-11.

Voda, M., \& Montes, Y.S. (2018) Descending mountain routes future: the North Yungas and Fagaras Geosystem`s comparative study. Geographia Technica, 13 (2), 152-166. 